\title{
Physiotherapy in Relation to the Treatment of Non-European Patients
}

\author{
Paper read by MISS LOIS DYER, M.C.S.P. \\ at the First International Congress of Physical Therapy in London, September 1953.
}

$\mathbf{T}^{\mathrm{H}}$ HE problem of giving Medical Services to the nonEuropeans in South Africa, in view of the fact that they constitute approximately 80 per cent. of the population and are a constant source of difficulty and infection, is of paramount importance and could be discussed end. lessly. All the difficulties and fundamental differences find their counterpart, though perhaps to a lesser degree in the application of Physiotherapy to this group of people.

The non-Europeans in South Africa comprise, the Bantu or native, the Coloureds, who are those of any mixed blood, the Indians, Malay and Chinese-in fact, anyone whose skin is not white. The Bantu form the largest group and it is about them that I am going to talk.

One's approach to the Bantu race is of necessity different from that used for the European. It is a largely primitive race which does not understand European methods of medical treatment, and even among the urbanised group, with which I have had most experience, at least 60 per cent. of the non-Europeans have treatment by their own people before attending Hospital.

They are used to the methods of their witchdoctors who spend four fifths of the time after a spot diagnosis, discussing what they consider is the pathology of the condition, and then prescribe their various herbs as remedies for this, that and the other symptom. The belief is still firmly held that illness is caused by evil spirits of their dead relatives and acquaintances, and this tends towards a certain fatalistic acceptance of illness.

I must quote an example to give you some idea of the superstition and mistrust against which medicine has to battle. An African Staff Nurse who was trained at one of the non-European Hospitals in Johannesburg, and who was a good nurse, decided to get married a couple of years after the completion of her training. This she did, and shortly afterwards she had a baby. The baby became ill, and this Staff Nurse first took her child to the witchdoctor, and only when its condition deteriorated did she bring it to the hospital. If that is the attitude of what was a reasonably intelligent native woman with a medical training, it is easy to imagine what the actions of the lay African public are. Time and again one has first to undo the damage done physically and psychologically by the witchdoctor, before progressing to the routine scientific treatment of the patient.

The language difficulty is of course a major one, and even with the use of intelligent interpreters, it is not easy to establish the relationship with the patient which one does when speaking the same tongue.

The African has no idea of prophylactic medicine and indeed usually does not come to the hospital unless his condition is very painful, or is sufficiently incapacitating to prevent his working.

Apart from the psychological factor which has to be combatted no matter what form of medicine the patient is to receive, there are very real difficulties encountered physically and economically, and I would like to try and give you a picture of some of them as met with in the Physiotherapy Department.

Firstly, the native does not understand the need for physiotherapy, and would usually far rather be given a bottle of medicine to help his broken leg and would be better pleased with it, no matter how vile the taste. We all know how difficult it is to explain to some Europeans why they are being made to use their muscles, and why they must be given breathing exercises when they complain bitterly that it is an operation on their knee that they are going to have! With the Africans, it is worth trying to explain simply what one is doing, but even though they smile and co-operate quite well while one is with them, it is obvious that they think this is another of the white man's idiosyncrasies to be accepted, not questioned and certainly not understood.

The high incidences of tuberculosis, venereal disease and malnutrition manifested in many forms, tends to lower the resistance of the Africans to general infection, although it is amazing considering their living conditions and complete lack of hygiene and knowledge of food values, that it is not even lower. Their constant exposure to disease and conditions of sepsis must stimulate the formation of vast numbers of antibodies and create a certain immunity.

Again, it is astonishing to see a patient who has perhaps been immobilised for six months with a fractured femur, the callus formation often being slow because of the low calcium production, come out of traction and within two or three weeks have full knee flexion. This is probably due to the fact that the primitive native still tends to use his joints naturally and has not had to undergo the abuses of joint function which our modern civilisation demands.

Most cases sent for treatment are due to trauma, since the African is exposed to many industrial hazards apart from the common causes of accidents among Europeans. There are many cases of assault, chiefly stab wounds and injuries caused by hitting each other with sticks and pieces of iron. This seems to be a favourite pastime particularly at the week-ends when many of them do not work, and drunkenness is common. Then one has the usual medical conditions to treat, plus an enormous number of septics. Burns are very common, primarily due to the primitive methods of cooking and heating which they employ.

I have rarely seen a case of fibrositis, and very few rheumatoids. The Bantu, however, appears to be more prone to osteoarthritis than the European, although it is interesting to note with this particular disease that the joints most commonly affected are quite different in the two races. Definite anatomical differences in the knee joints of the Bantu and European seem to account for the fact that medial meniscus injuries are extremely rare in the Bantu. It is only in the last few years, since so many have adopted the European dietary habits, together with the strain of city life, that one has seen cases of appendicitis, gastric ulcers and a certain evidence of psychological and functional illnesses.

Lead swinging was practically unknown until the last War, when the habit seemed to have been picked up in the Army. However, one still sees very little of it, chiefly because when an African is ill, he has no means of earning, since very few are entitled to unemployment benefits. He either has to get better quickly and return to full earning capacity, or he and his wife and children starve. This makes life much easier for the physiotherapist since the patients have a definite will to get better and co-operate well.

They are usually prepared to tolerate more pain than the European, and it seems that the pain threshold is much higher. They are renowned for their stoicism and unending patience.

Treatment in classes is very popular, as is work involving apparatus, and competition is keen, rather as it is with 
children. In fact one's approach is ofteh similar to that used with European children. Their basic knowledge of native crafts makes them particularly amenable to work in the Occupational Therapy department and the men, women and children produce some most beautiful articles.

One major technical difference in the treatment of the natives is caused by their pigmentation. When treating open areas the dosage is of course as for a European, but when treating the skin itself, I have found that one has to multiply the normal dose by about four times, and look very hard to see the reaction. Different tribes have different amounts of pigmentation and one has to grade the dosage accordingly.

Largely because of the bed shortage, patients are only kept in Hospital if they are really ifl, and so they are discharged as soon as possible. This again is a tribute to their amazing stamina, for one could not possibly do this with Europeans.

This does raise a problem, however, in that attendance as an outpatient is always difficult, because of transport fares, and many cases are lost to us because of this important factor. As far as possible, those needing concentrated treatment are kept in, but it is not always practicable, nor very often does the patient desire it. In many Hospitals, the authorities even go as far as admitting babies as lodgers when their mothers are ill, to try and relieve the social problem of what to do with the child.

Most Africans prefer to get home as soon as possible. This creates difficulty as far as long term cases are concerned, such as paraplegics. As soon as they are capable of struggling about, they are anxious to go back to their kraals, and one never seems able to continue long enough to obtain a 'really first class result.

Another problem is that of trying to make the African realise the importance of wearing appliances which may have been issued to him. They often cause discomfort, and so he removes them. Plasters are made two or three times stronger than those for Europeans, to withstand the wear and tear they must endure in the native's way of life, but many is the time I have seen a plaster cut and altered because the patient has found it uncomfortable or inconvenient. The same problem seems to arise over home exercises, whose value they seem unable to appreciate.

Once the patient is, discharged from hospital, it is very hard to make him realise the importance of being able to follow him up and this is a great drawback as far as records are concerned. If he feels well, the African sees no point in attending the hospital.

Another aspect which unfortunately has to be faced far too often is that a patient arrives at the Department frightened and slightly on the defensive because of the treatment he has received in other departments. NonEuropean Hospitals are always overcrowded and understaffed it seems, and one has to have a great deal of patience to cope with the enormous number of cases. It is easy to become irritated by their lack of understanding and apparent stupidity in many instances, and it must be confessed it is not always pleasant to work with the African whose odour is different from that of the European, and whose habits and clothing are not the cleanest. On top of his initial fear and mistrust of the hospital methods, the African finds himself bullied and shouted at far too frequently, when a little tolerance and understanding would gain his confidence and eompletely alter his attitude.

I find treating non-Europeans a most stimulating and satisfying experience, and provided they are treated with common decency and consideration, they are just as grateful for their treatment, and often more so, than the average European. Nearly all of them are amenable, polite and eager to help if they can.

I look forward to the day, which is not far off, when we shall be able to train non-European physiotherapists to treat their own people, so that with many of the present barriers thus lifted, we shall see really worth while work and another progressive step will have been taken towards producing a responsible African race.

\section{The most vitalising} of all measures

That was the description given 18 years ago by a distinguished lecturer to general ultra-violet light therapy; it still holds good today. Except in certain selected conditions where the use of ultra-violet is definitely contra-indicated, it can be said that there is no invalid or convalescent whose condition cannot be ameliorated by the judicious use of ultraviolet rays. The impact of this high-energy radiation upon the skin sets into motion a train of photochemical and physiological processes to which the whole body responds, thus giving fresh impetus to the processes of healing. In spite of the spectacular results obtained in other fields of therapy in recent years, no other single method has produced such beneficial effects in the human system, and with such complete lack of adverse sequelæ.

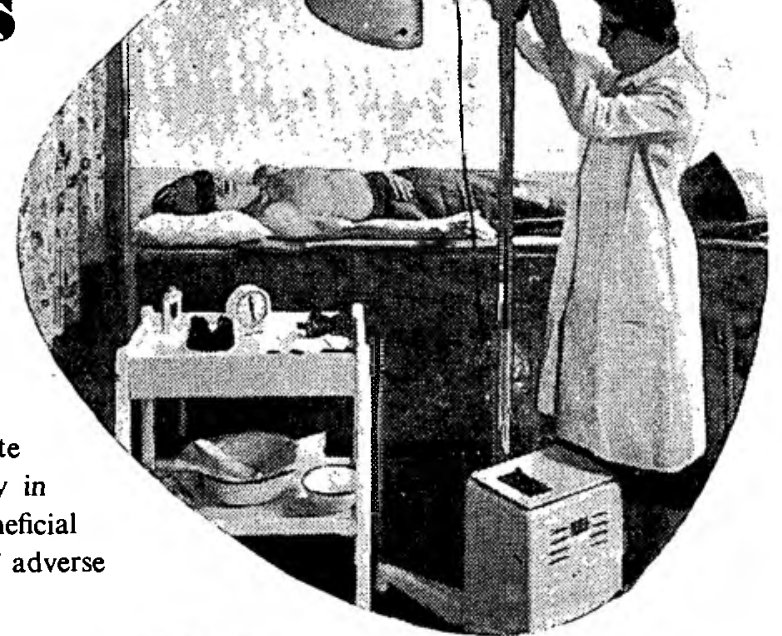

\section{Supply and service through:}

The British General Electric Co. Ltd.
Magnet House, Loveday \& Anderson Streets,
JOHANNESBURG.
Branches: Cape Town, Port Elizabeth, Salisbury, and Bulawayo.

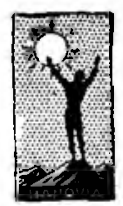

HANOVIA

LT D .

SPECIALISTS IN ACTINOTHERAPY EQUIPMENT.

SLOUGH - ENGLAND 